\title{
BROKSTUKKEN VAN EEN ILLUSIE HOE BRONS WON VAN STEEN
}

De schaarse resten van de Xiyang lou, de 'Europese paleizen' in de noordoostelijke uithoek van het terrein van de voormalige Yuanming Yuan, de 'Tuin van Volkomen Helderheid' - in de late $19^{\circ}$ en de $20^{e}$ eeuw onder Westerlingen in China beter bekend als het 'Oude Zomerpaleis', ${ }^{1}$ zijn tegenwoordig waarschijnlijk beroemder dan in de tijd dat die Xiyang lou in opdracht van de Qing-keizer Qianlong (r. 1736-95) werden ontworpen, gebouwd, en kortstondig gebruikt als onderkomen voor de keizerlijke verzameling van klokken, speeldozen, spiegels en andere Westerse curiosa. De gebouwen waren niet ruim genoeg om werkelijk door de keizer of zijn familie of leden van het hof bewoond te worden, ze dienden als opslag- en uitstallingsruimte, of ze huisvestten de machinerie en de reservoirs voor de fonteinen. Hun aanblik leverde verstrooiing, als doel voor een wandelingetje op een verloren achternamiddag, en diende als achtergrond voor keizerlijke verkleedpartijen. ${ }^{2}$ In die zin waren ze in hun geheel een trompe l'oeil-effect en meer façade dan interieur. Hun verwoesting en plundering in 1860 door Franse en Britse troepen heeft met een lithografie de geïllustreerde pers en daarna de geschiedenisboekjes gehaald (afb. 1). Het gebouw waarvoor de ongeregeldheden zich afspelen, is te herkennen als de westelijke façade van de Haiyantang - het onderwerp van dit artikel - maar in ongeschonden staat zullen ze, buiten de directe keizerlijke entourage, slechts door weinigen gezien zijn.

Dat ze toch een plaats hebben gekregen in het collectieve geheugen, komt zeker door de set gravures die in opdracht van Qianlong door leerlingen en assistenten van de jezuïeten-hofschilders van de façades van de Europese paleizen en de andere 'vista's' zijn gemaakt. Van de 20 kopergravures van $50 \times 88 \mathrm{~cm}$. naar tekeningen van de Manchu Yi Lantai (actief c. 1738-1786), met links of rechts in de bovenhoek in het Chinees de naam van het gebouw, de windrichting van het aanzicht, en het nummer in de serie, zijn afdrukken in verschillende bibliotheken bewaard gebleven (afb. 2).

\section{Paleizen achter fonteinen}

De aanleiding voor de bouw van de Xiyang lou was, naar men zegt, een afbeelding van een Europese fontein die de interesse van Qianlong had gewekt. ${ }^{3}$ De keizer had Giuseppe Castiglione (1688-1766), die al sinds 1715 aan het hof werkzaam was, die zowel zijn vader Yongzheng als zijn grootvader Kangxi als hofschilder gediend had en groot vertrouwen genoot, gevraagd of er onder zijn collega-jezuïeten wellicht iemand in staat zou zijn iets dergelijks te maken. Uiteindelijk zou de eer te beurt vallen aan de Fransman Michel Benoist.

Vader Benoist (1715-74), sinds 1746 in Peking, was van huis uit wiskundige en astronoom, maar had bovendien in Frankrijk enige hydraulische ${ }^{2023}$ kennis 


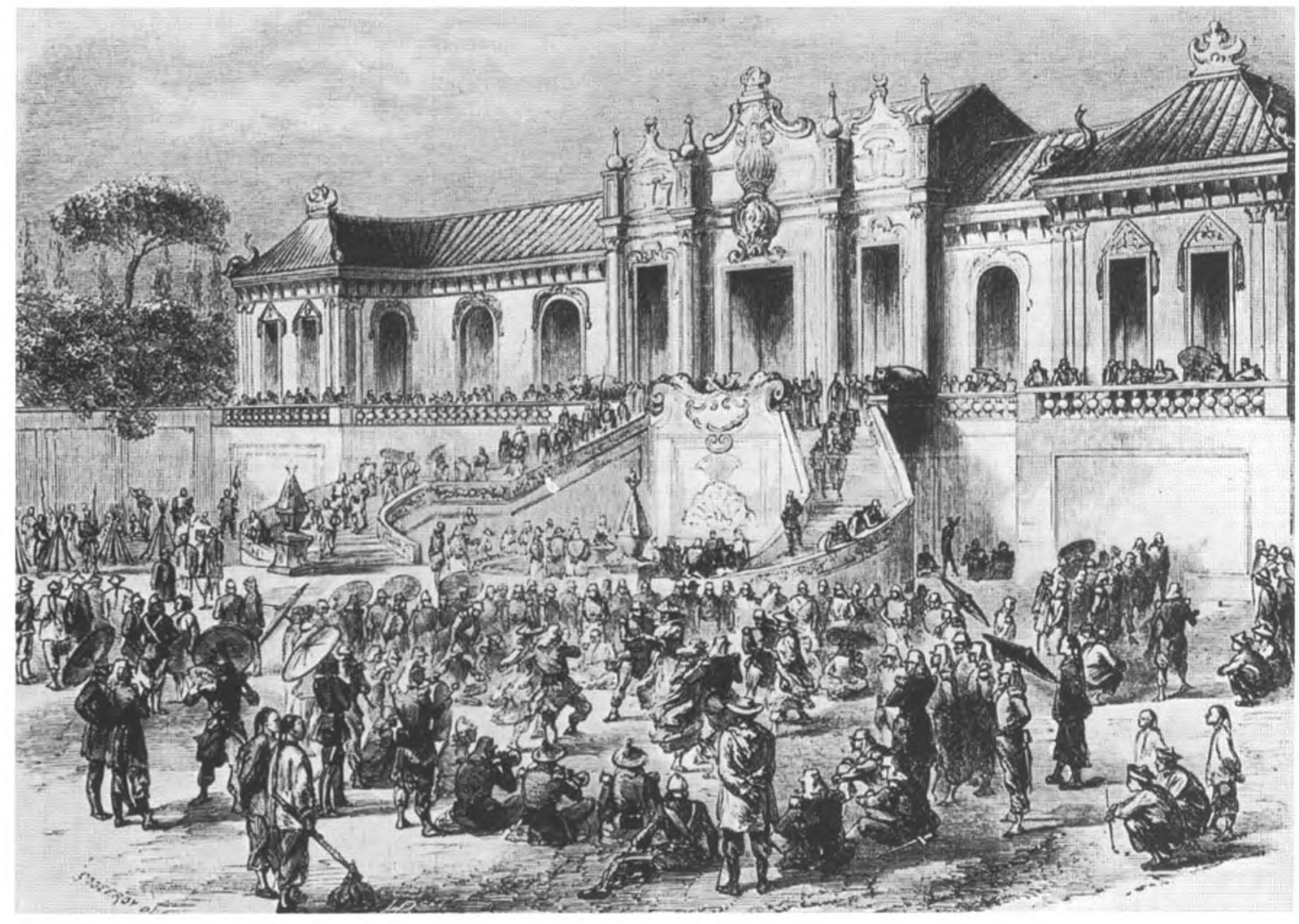

Afb. 1

Plundering van de Yuanming Yuan in 1860, lithografie, Parijs, 22 December 1860. De prent is oorspronkelijk verschenen in L'Illustration en is gesigneerd 'Sodeeroy Durand'. Uit: Geremie Barmé, Op. cit., p.134, fig. 39. opgedaan. Het model dat hij wist te produceren bracht de keizer dusdanig in verrukking, dat deze ter plaatse besloot dat alleen een paleis in Europese stijl een dergelijk wonder recht zou kunnen doen, en hij gaf Castiglione de opdracht om daar samen met Benoist aan te gaan werken. Zij op hun beurt betrokken weer andere Westerse missionarissen met opportune kennis of vaardigheden in het project, zoals Jean-Denis Attiret (1702-68) en Ignatius Sichelbarth (1708-80), om alleen de bekendste te noemen, en uiteraard werden er Chinese specialisten bij de planning ingeschakeld (schilders, bouwmeesters), en uiteindelijk ambachtslieden om het allemaal uit te voeren: honderden timmerlieden, metselaars, steenhouwers, tegel- en pannenbakkers, dakdekkers, en niet te vergeten makers van kunstsmeedwerk voor de hekken, en talloze tuinlieden.

Vader Benoist die aldus, goedschiks of kwaadschiks, tot fonteinenbouwer was gebombardeerd, zou het grootste deel van de rest van zijn jaren in Peking besteden aan het verfraaien van de Europese Paleizen met waterwerken in alle soorten en maten. Vader Antoine Gaubil schrijft op 14 november 1757 aan Monsieur de l'Isle van de Académie des Sciences in Parijs (in verband met het Observatorium op de Pekingse stadsmuur, waar de jezuïeten officieel als sterrenkundigen werkzaam waren) dat het de bedoeling was geweest dat "Vader Benoist voor Peking de onregelmatigheden in de straalbreking zou onderzoeken, maar dat hij daarmee gestopt is omdat hij geheel in beslag wordt genomen door de bezigheden die hij voor de keizer bij zijn Zomerpaleis verricht, op 2 mijlen afstand van hier". ${ }^{4}$ Een jaar eerder had hij al gemeld dat Vader Benoist het te druk had bij het keizerlijk zomerpaleis om astronomische

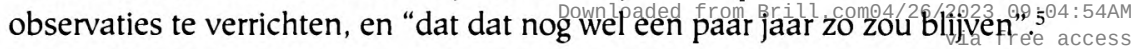


De bouw verliep in twee stadia: eerst, van 1747 tot 1751 , werden drie 'vista's' aangelegd binnen een noord-zuid georiënteerde strook van $320 \times 85 \mathrm{~m}$..

Het tweede stadium, van 1756 tot 1759 , zag haaks daarop een smal lint verschijnen van $60 \mathrm{~m}$. diep en alles bij elkaar $770 \mathrm{~m}$. lang, met zeven aanzichten langs de noordrand van de inmiddels ook aangelegde Changchun Yuan. In 1768 kwam daar nog een onverwachte 'annex' bij, (achter de Grote Fontein in het midden van het 'lint') teneinde een geschenk van zes wandtapijten naar ontwerpen van François Boucher, die in geen van de tot dan toe gebouwde Xiyang lou pasten, te kunnen huisvesten. Het is niet bekend wie als architect is opgetreden voor deze toegift, twee jaar na het overlijden van Castiglione.

Het gebouw dat in de lithografie van afbeelding 1 op het punt staat geplunderd en verwoest te worden, was het grootste, en in de 'horizontale' strook van west naar oost geteld het tweede van de Europese paleizen, de Haiyantang (het Paleis van de Kalme Zee), met voor de westelijke façade een bassin met een zowel simpele als ook fraaie en omvangrijke 'waterklok'. Aan weerszijden van een grote marmeren rocaille schelp zitten daar de 12 figuren van de Chinese dierenriem, 12 dieren gekleed in lang (literaten-) gewaad, en ieder met een attribuut - in de gereproduceerde gravure helaas niet alle precies te identificeren. De dierfiguren worden geacht te corresponderen met de 12 dubbele uren waarin het Chinese etmaal werd verdeeld. ${ }^{6}$ Op de rand van het bassin zitten ze om en om links en rechts, te beginnen rechts van de schelp in het midden (van voren gezien) met de Rat, dan links van het midden de Os, dan weer rechts de Tijger, links de Haas, en zo verder. Naar men zegt, spoot ieder dier twee uur lang water (uit de bek), en om twaalf uur spoten ze allen tegelijk. Zoals we nu weten, maar wat aan de gravure niet te zien is, waren de aangeklede lijven van de dierenbeelden, net als de andere ornamenten aan en op de Xiyang lou in (zand)steen of marmer uitgevoerd, maar de koppen van de dieren, inclusief de hals, dus de spuitende fountainheads, waren van brons. En waar van de waterklok/fontein (op de loodzware schelp na, die nog min of meer intact ter plaatse ligt $)^{7}$ alleen puin en brokstukken zijn overgebleven, waren de fraaie bronzen dierenkoppen 'buit'. Ze zijn over verschillende verzamelingen verdeeld geraakt, en halen onveranderlijk het nieuws, iedere keer wanneer er één op de markt verschijnt.

Overigens heeft, vergeleken met de traditionele houtbouw van de paleizen en paviljoens in de rest van het Oude Zomerpaleis, het kleine hoekje van de Europese paleizen, met meer elementen in steen en marmer, de plundering en brandschatting eigenlijk relatief goed doorstaan. Er is weliswaar geen enkel gebouw intact gebleven, maar juist de Westers vormgegeven onderdelen, zoals balustrades, kroonlijsten, kapitelen en voetstukken van zuilen, waren in de duurzamere materialen uitgevoerd, zodat de 'schilderachtige' ruïnes nog steeds een indruk kunnen geven van de unieke stijl. En zoals Regine Thiriez, die alle historische foto's heeft geïnventariseerd, al opmerkte, zijn ze door hun bijzondere vormgeving grotendeels gespaard gebleven voor de gebruikelijke 'sluipende plundering', waarbij steeds kleine hoeveelheden materiaal worden ontvreemd voor hergebruik (in locale bouwsels). Gewone bakstenen verdwenen daarbij altijd het eerst, maar elementen met een exotisch (Westers) randje of andere versiering waren natuurlijk minder goed bruikbaar. Zelfs gemakkelijk te verwijderen materiaal werd zo soms versmaad 


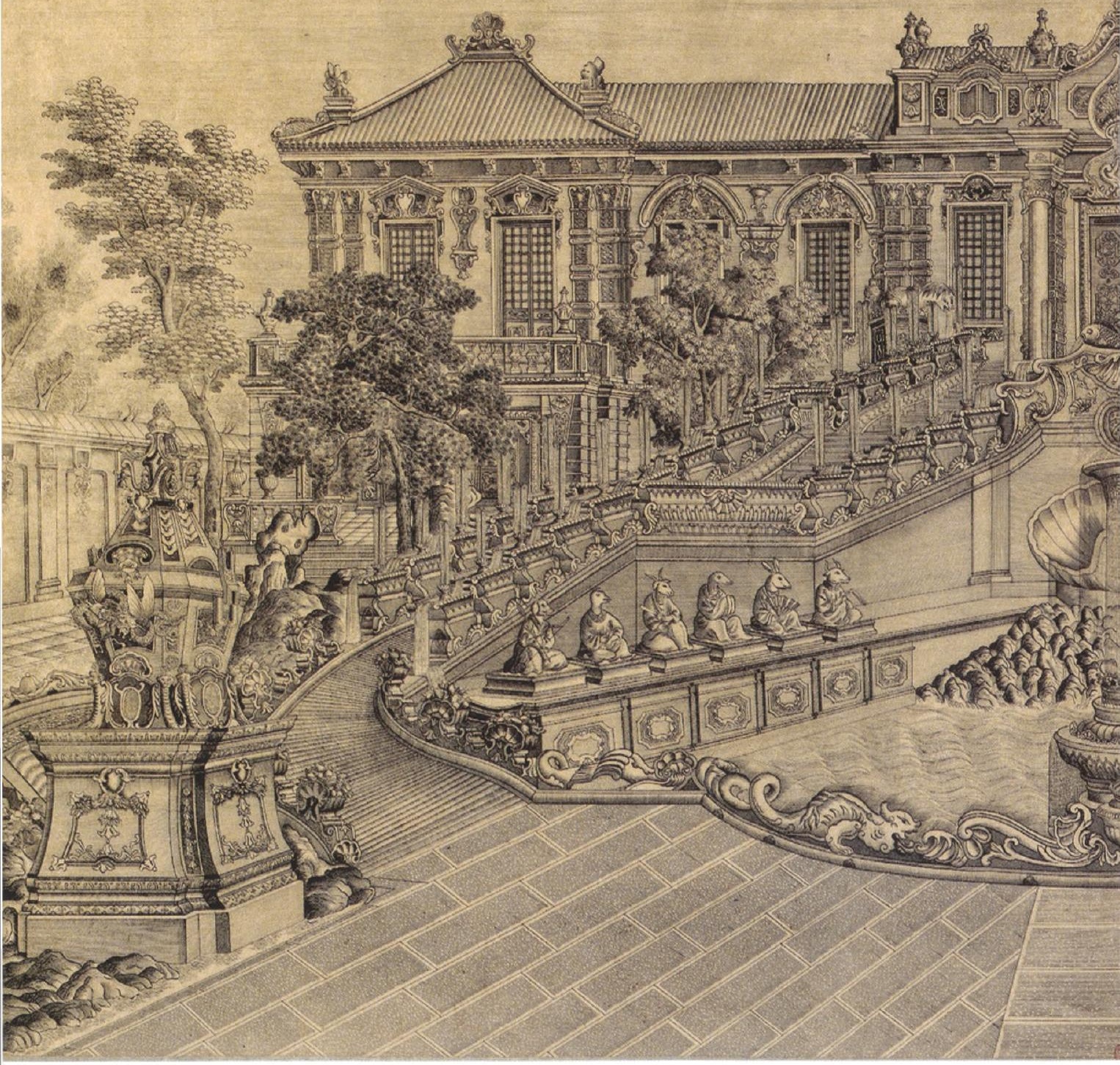

Afb. 2

De westelijke façade van de Haiyantang,

kopergravure, $50 \times 88 \mathrm{~cm}$., 1783, naar

Yi Lantai (actief c.1738-'86),

Changchun Yuan shuifa tu, no. 10.

Bibliothèque Nationale, Parijs

[BnF, DRE-OE-18(A)]. 

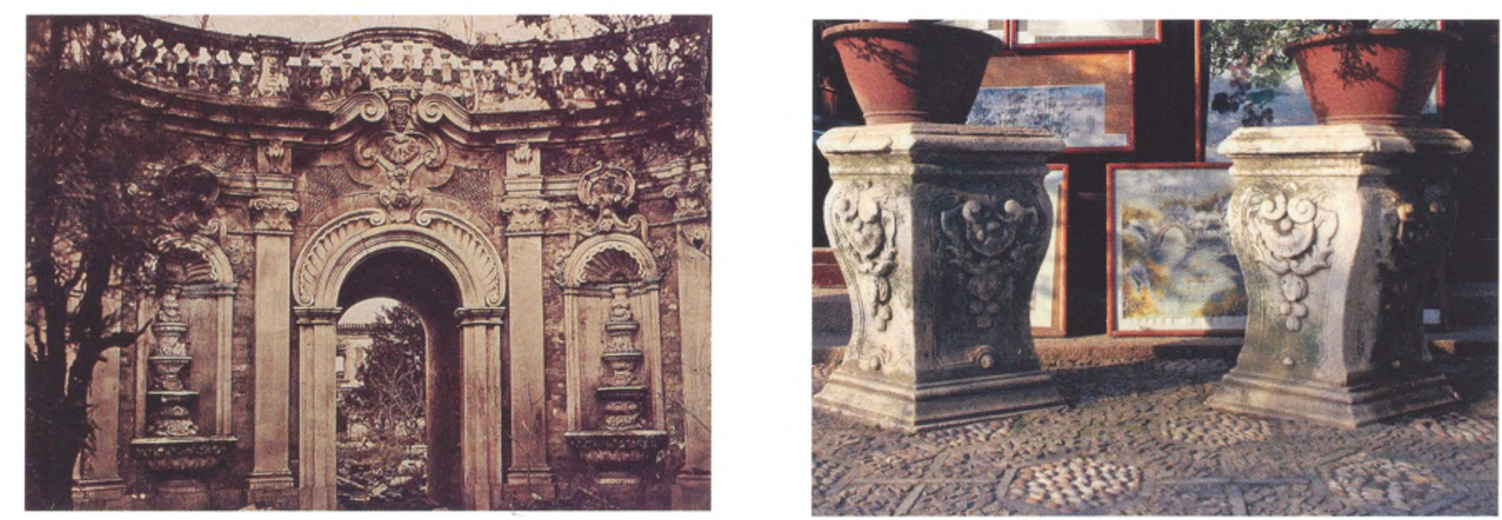

Afb. 3 (links)

De oostpoort van de Voliere, gefotografeerd door Thomas Child in 1877 . Orientations, 19/11 (1988), p. 63, fig. 4.

Afb. 4

Stenen sokkels, vermoedelijk afkomstig uit de Yuanming Yuan, teruggevonden in een park in Suzhou (de Zhuozheng Yuan). Uit: Scattered remains of Yuanmingyuan, Beijing, 2007, p. 117. zoals de stenen bloemenvazen in de nissen van de poort van de Volière (afb. 3). In 1877 nog gefotografeerd door Thomas Child, stonden ze daar in 1924 nog steeds toen de poort werd gesloopt.

Wel heeft 'ordinaire' koperdiefstal ongetwijfeld bijgedragen aan de vernietiging van juist de fonteinen - met het slopen van de leidingen uit het binnenwerk ging ook de 'body' van de fontein verloren - in het geval van de waterklok wel heel letterlijk: van de 12 dierenlijven-in-literatengewaad is zelfs geen herkenbaar fragment overgebleven.

Een door de directie van de huidige "Yuan Ming Yuan Garden" in 2007 uitgegeven boek (uitsluitend in het Chinees) laat zien waar op dit moment nog wel herkenbare fragmenten of grotere elementen te vinden zijn.

De verscheidenheid aan locaties is verbluffend, maar de elementen zelf zijn minder interessant dan gehoopt (afb. 4). Bovendien vind ik de overeenkomst met het ernaast gereproduceerde detail uit de gravures niet altijd even overtuigend. Verder is hier ook van de in 1860 door de plunderende troepen geroofde objecten de Franse 'buit' te zien, die zich in het kleine "Chinese museum van Keizerin Eugénie” bevindt, in het Paleis van Fontainebleau. Opvallend is vooral dat de Europese curiosa - die in de Xiyang lou werden opgeslagen - hier schitteren door afwezigheid, het is uitsluitend porselein (van duidelijk keizerlijke kwaliteit), jade en cloisonné email wat getoond wordt.

\section{De huidige status van de bronzen dierenkoppen}

Een oorspronkelijk aan het Volksbevrijdingsleger gelieerde semi-private organisatie, de Poly Corporation, die voorheen wapens verhandelde, maar zich tegenwoordig inzet voor de 'repatriëring' van ontvreemde Chinese kunstvoorwerpen, toont in haar kleine museum-annex-veilinghuis in Peking, ${ }^{8}$ behalve antieke bronsvaten en boeddhistische tempelbeelden, ook de vijf (van de twaalf) bronzen dierenkoppen van de Haiyantang-fontein die inmiddels zijn verworven - althans, wanneer ze niet tijdelijk elders in bruikleen zijn, wat helaas nogal vaak schijnt voor te komen. Men zegt aan het completeren van deze serie op dit moment de allerhoogste prioriteit te geven. De Tijger, de Aap, en de Os zijn al sinds april 2000, toen ze bij Christie's Hongkong werden verkocht, in het bezit van de Poly Corporation. Het Zwijn was in 1987 in een veiling bij Sotheby's New York aan een Amerikaanse verzamelaar verkocht, maar werd teruggekocht door de scheepsmagnaat, Macau'se gokpaleizenkeizer en patriot 'Stanley' Ho, ${ }^{9}$ voor zes miljoen CNY, en aan Poly geschonken. Het Paard is in 2007, net voor de openbare veiling 

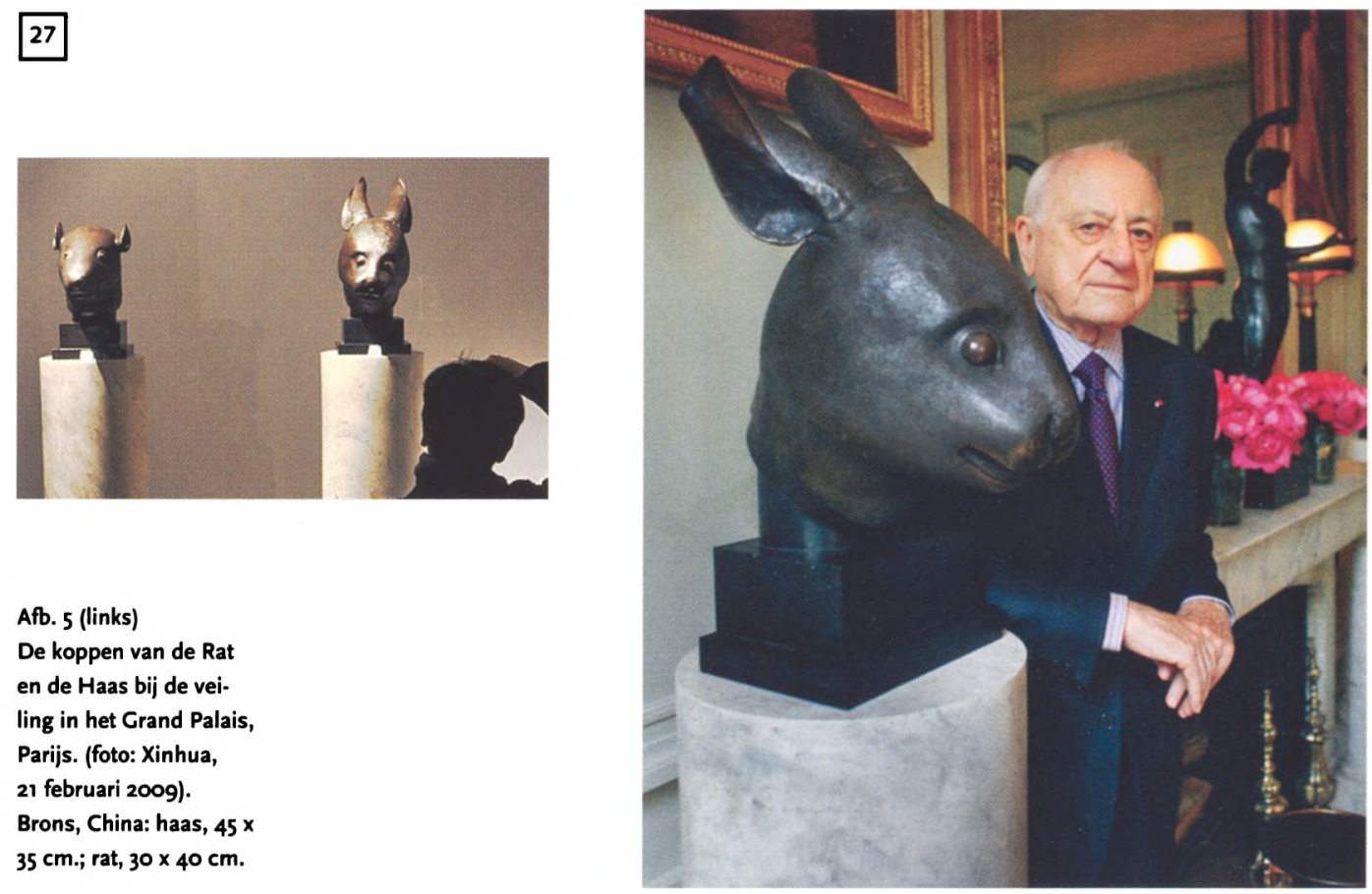

Afb. 5 (links)

De koppen van de Rat en de Haas bij de veiling in het Grand Palais, Parijs. (foto: Xinhua, 21 februari 2009). Brons, China: haas, $45 \mathrm{x}$ $35 \mathrm{~cm}$.; rat, $30 \times 40 \mathrm{~cm}$.

Afb. 6 Kop van de Haas, uit de nalatenschap van de Franse modekoning Yves Saint Laurent, naast zijn weduwnaar Pierre Bergé. Uit: Leidraad, Zomer 2009, p.26 (foto: Marc de Haan). bij Sotheby's, eveneens door Stanley Ho voor Poly (en China) opgekocht en gered. Veel opzien baarde tenslotte de veiling van de nalatenschap van de Parijse modekoning Yves Saint Laurent, door Christie's in het Grand Palais, eind februari 2009, waarin opnieuw twee dierenkoppen (van de Haas en de Rat) onder de hamer gingen (afb. 5). Cai Mingchao, een kunsthandelaar uit Xiamen in zuidoost China, aan de kust tegenover Taiwan, deed beide keren het winnende bod (tweemaal 14 miljoen euro), maar weigerde vervolgens te betalen, volgens één bron omdat de objecten al Chinees eigendom waren, maar volgens een andere had hij eenvoudigweg het geld niet, en zou hij ook nooit van plan zijn geweest te betalen. Naar verluidt zijn ze nu teruggenomen door Pierre Bergé, de weduwnaar van Yves Saint Laurent, en voorlopig weer in de kluizen van de Fondation Saint Laurent verdwenen (afb. 6).

In een artikel in Wapedia, de mobiele Wikipedia, werd op 25 juni 2010 overigens gesuggereerd dat de vijf nog niet gelokaliseerde koppen opgeslagen liggen in het British Museum in Londen en het Louvre in Parijs - een idee dat natuurlijk rijk is aan precedent, maar waarvoor geen enkele concrete aanwijzing bestaat.

Het laatste wapenfeit is op dit moment dan nog dat de Chinese hedendaagse kunstenaar Ai Weiwei (die van 3 april tot 23 juni van dit jaar in hechtenis zat) uitvergrote bronzen 'kopieën' van alle koppen heeft gemaakt, ${ }^{10}$ van c. 1,20 m. hoog, op c. 1,80 m. hoge bronzen staanders "suggesting abstracted lotus stems and leaves" 11 die, na deelname aan de Biennales van São Paolo vorig jaar en Venetië dit jaar, onder de titel Circle of Animals/Zodiac Heads waren opgesteld in New York (Grand Army Plaza, voor het Plaza Hotel aan Central Park, tot 15 juli), terwijl een tweede set te zien was in Londen (op de binnenplaats van Somerset House aan de Strand, tot 26 juni). Nog te verwachten tentoonstellingsdata (in de Verenigde Staten) zijn opgenomen aan het eind van dit artikel. 

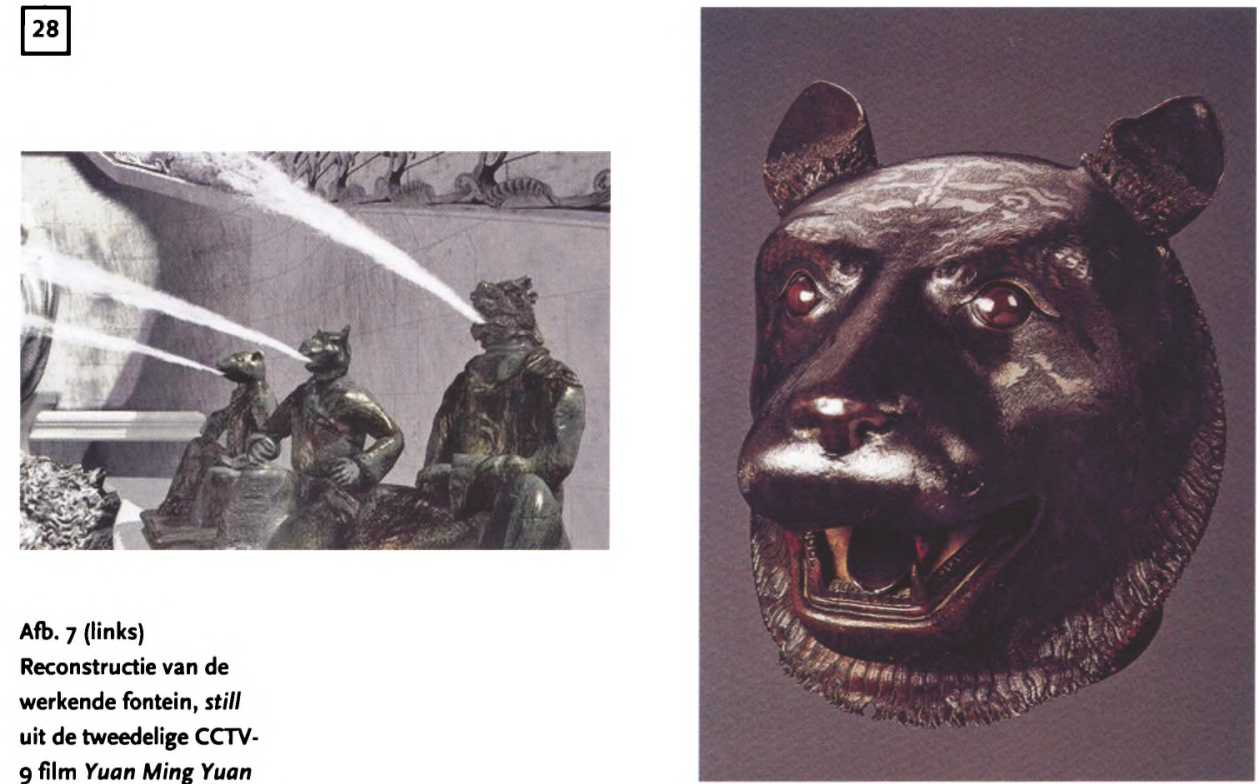

Afb. 7 (links)

Reconstructie van de werkende fontein, still uit de tweedelige CCTV9 film Yuan Ming Yuan - Garden of Gardens, 2010 (95:20 min.).

Afb. 8

Kop van de Tijger, brons, China, h. $45 \mathrm{~cm}$. (in 2000 geveild door Christie's Hongkong, gekocht door Poly). Uit: Qing tong pian, Taibei, 2002, p. 327.

\section{De twaalf cyclische dieren als 'Europese' ornamenten?}

Gebruikelijk commentaar bij de waterwerken van de Xiyang lou is altijd dat ze niet, zoals veel Europese fonteinen, waren 'gestoffeerd' met menselijk naakt - een begrijpelijke aanpassing aan de gevoeligheden van de keizerlijke opdrachtgever. Maar van daar naar het gebruiken van aangeklede dieren, en dan nog wel intrinsiek-Chinese symbooldieren (deze 12 vertegenwoordigen de "12 Aardse Takken" die in combinatie met de "10 Hemelse Stammen" verantwoordelijk zijn voor de 60-jarige cyclus die vanouds de basis vormt voor de Chinese tijdrekening) is wel een heel grote stap, zeker in een complex waarvan de bedoeling was dat het in 'Westerse stijl' werd vormgegeven. Wat Castiglione kan hebben bewogen om zo van zijn opdracht af te wijken, is niet direct duidelijk. De attributen zouden misschien kunnen helpen om de bedoeling achter het gebruik van juist dit twaalftal te verhelderen, maar van de attributen zijn er, zoals gezegd, slechts enkele duidelijk te identificeren. Ik herken alleen met zekerheid, in het rijtje links van de schelp, als eerste bij de Os een vliegenkwast, en daarnaast bij de Haas een waaier. De Slang heeft 'iets kleins' - met andere woorden: het zou een parel kunnen zijn maar het is eenvoudigweg niet te zien, en daarnaast heeft de Ram dan misschien een zwaard, maar het zou ook een fluit of iets dergelijks kunnen zijn. Aan het eind van diezelfde rij is dan alleen nog, bij het Zwijn, wèl heel duidelijk een boog en pijlen te zien. Bij de rij aan de andere kant is het niet beter, eerder slechter: ik denk bij de Hond (helemaal rechts) een bamboe staf en eventueel een rozenkrans te zien, de Aap (links daarnaast) heeft een lange speer en een ring, of een spiegeltje, en de Rat (helemaal links) het een of ander blaasinstrument, maar daarmee houdt het eigenlijk op.

Deze attributen laten zich ook niet tot een bekende reeks herleiden - zoals de (Acht) Kostbaarheden, de (Zeven) Schatten, of bekende boeddhistische of daoïstische series van emblemen, noch zie ik enige verbinding of gelijkenis met de (Twaalf) keizerlijke insignia, of de (Twaalf) innerlijke organen. In het beeld uit de C.C.T.V.-documentaire over de Yuanming Yuan zitten de dieren

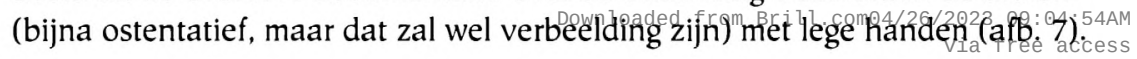


Misschien nog wel het meest specifiek Chinese 'attribuut', in de zin van: voor ingewijden door een symbool of embleem aangeven met wie of wat we hier te maken hebben, is het duidelijk leesbare karakter wang (koning) in de vacht op het voorhoofd van de tijger ( $a f b .8$ ) - zoals dat hoort voor een tijger in China waar hij wordt beschouwd als koning van het dierenrijk (onze Westerse koning der dieren, de leeuw, is in China niet inheems). Merkwaardig is dan echter weer wat een officiële regeringswebsite in 2007 hierover te zeggen had. Onder het kopje "The Returned National Treasures of Yuanmingyuan" zijn daar kleine foto's van de dierenkoppen (op hun Poly-sokkels in hun Poly-vitrines) opgenomen, met een kort commentaar. De tekst bij de tijgerkop meldt dat "deze totaal verschilt van traditioneel-Chinese afbeeldingen van de tijger, omdat zonder het teken wang op zijn voorhoofd, men hem voor een leeuw zal aanzien. Het is zo typisch een mengvorm van de kunst van Oost en West". ${ }^{12}$ Het voorhoofd van de hierbij afgebeelde tijger is inderdaad geheel 'kaal', en spiegelend glad, in tegenstelling tot de tijgerkop van onze afbeelding 8 , uit de Taiwan-catalogus van vijf jaar eerder. Ik heb hiervoor geen verklaring.

\section{Castiglione laat zich niet reconstrueren}

De handen van de dierfiguren in de gereconstrueerde waterklok van afbeelding 7 zijn niet alleen leeg, ze zijn ook buitenproportioneel grof en groot, en dat lijken eigenschappen van alle pogingen tot hernomen Yuanming Yuanvormgeving. ${ }^{13}$ Castiglione liet en laat zich niet zo gemakkelijk navolgen. De huidige "Yuan Ming Yuan Garden" huisvest behalve de originele ruïnes, ook een of meer exposities van modellen en replica's, in het bijzonder van de waterklok-dieren, die op dezelfde (onaangename) manier afwijken van het beeld dat zich uit de gravures in ons hoofd had genesteld. Er zijn vitrines met alle bronzen koppen op een rij, die onderling wilde verschillen in stijl vertonen, en de drakenkop heeft hier bijvoorbeeld een bal in de bekmaar ook vitrines met alle complete dieren, die nu geheel in brons gegoten zijn (of in een brons-substituut, dat is niet goed te zien). In het algemeen is dat geen verbetering. Alles lijkt dikker te zijn geworden, met minder detail in het reliëf. En behalve grote en grove handen hebben sommige van de dieren nu ook heel dikke blote voeten met vlezige tenen gekregen - terwijl in het origineel geen enkele voet of teen te zien was. ${ }^{14}$

Ellen Uitzinger heeft een grafische kunstopleiding aan de voorloper van de Rietveld Academie afgerond, en (jaren daarna) een studie Sinologie in Leiden. $Z$ ij gaf daar later het college 'kunst en materiele cultuur van China', en maakt tegenwoordig deel uit van de redactie van Aziatische Kunst. Naast kunst, gaat haar interesse in het bijzonder uit naar (keizerlijk) ritueel, en eetcultuur.

\section{Literatuur}

Geremie Barmé, 'The Garden of Perfect Brightness, a life in ruins,' East Asian History 11 (1996), pp. 111-158.

Michèle Pirazzoli-t'Serstevens (red.), Le Yuanmingyuan - Jeux d'eau et Palais Européens du XVIIle Siècle d la Cour de Chine, Parijs, 1987.

Idem, 'The emperor Qianlong's European Palaces', Orientations 19/11 (1988), pp. 6171.

Régine Thiriez, 'Les Palais européens du Yuanmingyuan à travers la photographie: 1860-1940.' Arts Asiatiques 45 (1990), pp. 90 -969aded from Brill.comø4/26/2023 09:04:54AM 
Qingtong pian: lai zi Beijing Baoli Bowuguan [Bronzen uit het Poly Museum in Peking], Taibei, 2002.

Yuanmingyuan liusan wenwu [Scattered remains of Yuanming Yuan], Beijing, 2007.

Chang Wan-chen, 'Yuanmingyuan items in the collection of the Palace of

Fontainebleau', Arts of Asia 38/3 (2008), pp. 101-117.

\section{Agenda van Ai Weiwei's "Zodiac/Circle of Animals" in de Verenigde Staten}

- 1/09/2011-15/02/2012: Los Angeles County Museum of Art (LACMA), California.

- Winter 2011/Lente 2012: Hermann Park, Houston, Texas.

- 1/10 - 31/12 2012: The Andy Warhol Museum \& Carnegie Museum of Art, Pittsburgh, PA.

- Herfst 2012: Hirshhorn Museum \& Sculpture Garden, Washington DC.

\section{Noten}

1. Teneinde het complex te onderscheiden van de Yihe Yuan, het (jongere) Zomerpaleis van de keizerin-weduwe Cixi - bekend van de Marble Boat en de Long Corridor.

2. Een schilderij in het Nationaal Paleismuseum (in Taibei, Taiwan), of althans een dia in een serie uitgegeven door dit museum, toont keizer Qianlong en een van zijn gemalinnen of concubines (geflankeerd door twee eunuchen en een dienstmeisje) gezeten op het bordes van de Fangwaiguan, de Belvédère (herkenbaar aan de ovale ramen), het eerste gebouw op de 'horizontale' oost-west strook. De vrouw is gekleed in een Frans herderinnen-kostuumpje à la Marie Antoinette. De keizer zelf is niet verkleed. (No. 206 in de serie Zhongguo tongshi huandengpian, "Overzicht van de Chinese geschiedenis in dia's").

3. Bijvoorbeeld in de Franse kopergravure "L'Arc de triomphe de Versailles" (c. 1680), het obligate voorbeeld van Westerse paleistuinaanleg, een prent die zeker in de bagage van de paters te vinden zal zijn geweest.

4. Antoine Gaubil S.J., Correspondance de Pékin 1722-1759, Genève, 1970, p. 849.

5. Idem, p. 843.

6. De Rat (11 p.m.-1 a.m.); de Os (1-3 a.m.); de Tijger (3-5 a.m.); de Haas (5-7 a.m.); de Draak (7-9 a.m.); de Slang (9-11 a.m.); het Paard (11 a.m.-1 p.m.); de Ram (1-3 p.m.); de Aap (3-5 p.m.); de Haan (5-7 p.m.); de Hond (7-9 p.m.); het Zwijn (9-11 p.m.).

7. Zie Wan Yi et al. (red.), Life in the Forbidden City, Hongkong 1985, p. 277, pl. 430.

8. Geopend voor publiek sinds december 1999, en zeker de moeite waard: Baoli Bowuguan, Poly Plaza, 14 Dongzhimen Nandajie, Dongcheng District, Beijing.

9. Zijn Chinese naam is Ho Hung-sun. Hij is een kleinzoon van Ho Fook, die een jongere broer was van de welbekende Sir Robert Hotung.

10. In het geval van de nog ongetraceerde exemplaren, vermoedelijk gebaseerd op de gravure, of op een Chinees-conventionele weergave, zoals bijvoorbeeld bij de Draak voor de hand ligt.

11. Roberta Smith in New York Times Review (online, 4/5/2011, gepubliceerd twee maanden nadat Ai gevangen gezet was): "the bases also resemble stakes, which adds a slight touch of gallows humor."

12. www.culturalink.gov.cn/2007-11/14

13. Ik heb eerder al iets dergelijks opgemerkt over de Yuanyingguan die twee jaar na Castiglione's dood aan de Xiyang lou werd toegevoegd ('incongruent' en 'overblown'). Zie 'For the man who has everything - Western-style exotica in birthday celebrations at the court of Ch'ien-lung', in Leonard Blussé en Harriet T. Zurndorfer (red.), Conflict and Accomodation in Early Modern East Asia, Leiden 1993, p. 238.

14. Zoeken onder (Yuanmingyuan_Haiyantang_bronze replicas) levert al snel resultaat. Zoek en huiver... 